\title{
Hysteroscopic evaluation in infertile patients: a prospective study
}

\author{
Latika Sahu*, Anjali Tempe, Sweta Gupta
}

Department of Obstetrics \& Gynecology, Maulana Azad Medical College and Associated Lok Nayak Hospital, New Delhi, India

Received: 2 December 2012

Accepted: 14 December 2012

*Correspondence:

Dr. Latika Sahu

E-mail: latikasahu@gmail.com

\section{ABSTRACT}

Background: Hysteroscopy is the gold standard procedure for uterine cavity exploration. However, hysteroscopy is only recommended by the WHO when clinical or complementary exams (ultrasound, HSG) suggest intrauterine abnormality or after in vitro fertilization failure. Nevertheless, many specialists feel that hysteroscopy is a more accurate tool. The aim of this prospective study is to assess the value of diagnostic hysteroscopy in a primary workup of infertility by describing hysteroscopy findings in a population of 324 infertile patients during 18 months (December 2010 - May 2012).

Methods: We analysed prospectively 324 infertile patients in gynaecology OT setting. Diagnostic video-assisted hysteroscopy was performed using a flexible hysteroscope. Hysteroscopy was performed with a standard sequence, inspecting the endocervical canal, uterine cavity, endometrium, and tubal ostia and findings recorded.

Results: Hysteroscopy was normal in $65.12 \%$ of patients. Cervico-isthmic abnormalities were present in $6.48 \%$ of patients with cervical stenosis being the major abnormality. Uterine cavity was normal in $86 \%$ of patients. Observed abnormalities were septate uterus in 10 cases, intrauterine synechiae in 16 cases, sub mucus myoma in 2 cases, deformed cavity in 10 cases and endometrial polyp in 2 cases. Ostial fibrosis was observed in 29 patients. Endometrial abnormalities (fibrosis, inflammation) were observed in 30 patients. Seven patients turned out to be of genital tuberculosis with endometrial biopsy. No significance was found regarding the total number of intrauterine pathologies when comparing the groups of primary versus secondary infertility.

Conclusions: Rates of abnormal findings in infertile patient who underwent diagnostic hysteroscopy was $34.88 \%$ in our study. Our data are an additional argument to suggest hysteroscopy as part of investigation in infertile woman. Routine diagnostic hysteroscopy should be part of an infertility workup in primary and secondary infertility.

Keywords: Primary and secondary infertility, Diagnostic hysteroscopy, Intrauterine abnormalities

\section{INTRODUCTION}

Hysteroscopy is a valuable diagnostic and therapeutic modality in the management of infertility. Hysteroscopy is the gold standard procedure for uterine cavity exploration It is widely accepted that a complete infertility workup should include an evaluation of the uterine cavity. Uterine abnormalities, congenital or acquired, are implicated as one of the causes of infertility. In fact, infertility related to uterine cavity abnormalities has been estimated to be the causal factor in as many as $10 \%$ to $15 \%$ of couples seeking treatment. Moreover, abnormal uterine findings have been found in $34 \%$ to $62 \%$ of infertile women. ${ }^{1}$
Today, hysteroscopy is considered the gold standard for evaluating the uterine cavity, and due to improved endoscopic developments, can be performed reliably and safely as an office procedure. ${ }^{2}$ Direct view of the uterine cavity offers a significant advantage over other blind or indirect diagnostic methods. The role of hysteroscopy in infertility investigation is to detect possible intrauterine changes that could interfere with implantation or growth, or both, of the conceptus, and to evaluate the benefit of different treatment modalities in restoring a normal endometrial environment.

The World Health Organization (WHO) recommends hysterosalpingography (HSG) alone for management of infertile women. ${ }^{3}$ The explanation for this discrepancy is that HSG provides information on tubal patency or 
blockage. Office hysteroscopy is only recommended by the WHO when clinical or complementary exams (ultrasound, HSG) suggest intrauterine abnormality ${ }^{3}$ or after in vitro fertilization (IVF) failure. ${ }^{4}$ Nevertheless, many specialists feel that hysteroscopy is a more accurate tool because of the high false-positive and false negative rates of intra uterine abnormality with HSG. This explains why many specialists use hysteroscopy as a firstline routine exam for infertility patients regardless of guidelines. 5 The aim of this study was to describe hysteroscopy findings in 324 infertile patients examine the role of diagnostic hysteroscopy in a basic infertility workup and to compare its use in primary versus secondary infertility. Data obtained from diagnostic hysteroscopies, performed for infertility investigation, were analyzed.

\section{METHODS}

This Prospective study included 324 infertile women who had undergone hysteroscopy as part of their infertility workup in IVF clinic of Maulana Azad Medical College and Lok Nayak Hospital between December 2010 - May 2012. Medical records were used for all relevant data.

Hysteroscopy was performed to look for and evaluate the presence of intrauterine abnormalities. A detailed explanation of the procedure was given by the operating surgeon, and all women signed an informed consent before undergoing the procedure. Diagnostic hysteroscopy was performed in operation theatre, using a $3 \mathrm{~mm}$ hysteroscope, under short general anaesthesia. Distention of the uterine cavity was accomplished with normal saline solution. The procedure was considered complete only when the entire uterine cavity and both tubal ostia were visualized. Uterine anomalies were diagnosed according to the American Society of Reproductive Medicine classification within the limits of hysteroscopy. The endocervical canal is then carefully evaluated also. At the end of the hysteroscopy, under direct vision, an endometrial biopsy sample was obtained for histologic examination when indicated. Statistical analysis was performed using the Fisher's exact test. A result of $p<0.05$ was considered significant.

When performing a diagnostic laparoscopy at the same time as hysteroscopy. The hysteroscopy is performed immediately after the diagnostic laparoscopy and before any operative laparoscopic procedures in order to minimize trauma to the uterine cavity and to limit the creation of artifactual lesions or bleeding.

\section{RESULTS}

Hysteroscopy was performed in 324 infertile women: 232 $(71.60 \%)$ were diagnosed with primary infertility and 92 $(28.40 \%)$ with secondary infertility. Age $<30$ years were $177(54.62 \%)$ patients and $147(45.38 \%)$ were of $>30$ years. In the group with secondary infertility, the parity ranged from 1 to 2 , the spontaneous abortions ranged from 0 to 7 , and induced abortions ranged from 0 to 2 .

The indications for performing a diagnostic hysteroscopy are summarized in Table 1. The most common indication for diagnostic hysteroscopy was as a part of an infertility workup (224 cases). Other indications included cases being part of a continuous workup either before IVF treatment or after a number of failed IVF cycles.

For infertility work up the hysteroscopies were done with contemporaneous laparoscopy. But the laparoscopy findings we have not taken in the evaluation for this study.

Hysteroscopy revealed a normal uterine cavity in 211 $(65.12 \%)$ women (Table 2). Majority of patients with normal hysteroscopy findings were less than 30 years of age and primary infertility.

No statistically significant difference was found in other uterine findings while comparing the 2 groups (Table 2). No significant difference in the rate of uterine pathology was found between women with primary and secondary infertility (33\% and 39\%, respectively).

Cervico-Isthmic abnormalities: Cervical stenosis seen in 21/324 (6.48\%), Cervical polyp 5/324(1.54\%).

Uterine cavity abnormalities: Intra uterine synechia 16/324 (4.93\%), Septate uterus 10/324(3.08\%), Submucus myoma 2/324 (0.62\%), Deformed cavity (Intra mural myoma, Mullerian anomalies) 15/324 (3.71\%), Endometrial polyp 2/324 (0.62\%).

Ostial abnormalities: Cornual fibrosis 29/324 (8.95\%), Inflammation 18/324 (5.55\%).

Endometrial abnormalities: Inflammation 9/324 (2.78\%), Fibrosis 17/324 (5.25\%), Hyperplastic 1/324 $(0.31 \%)$ Atrophic $3 / 324(0.93 \%)$.

The distribution of all these abnormal findings according to their infertility type (primary/secondary) is described in Table 3.

Complications of the procedure like perforation of the uterine cavity occurred in only $7(2.16 \%)$ cases. All cases were managed conservatively and the procedure had stopped with that.

All the uterine abnormalities were treated either in the same or subsequent operating setting. All cases were followed up till today. One patient with septate uterus and three infertile women with cervical stenosis had pregnancy following treatment of the uterine abnormalities. 
Table 1: Indications for hysteroscopy in 324 infertile women.

\begin{tabular}{|ccc|}
\hline Primary infertility No. $(\%)$ & Secondary infertility No. $(\%)$ & Indication \\
\hline $152(65.5 \%)$ & $72(78.2 \%)$ & As per infertility workup \\
\hline $73(31.4 \%)$ & $16(17.3 \%)$ & Before IVF treatment \\
\hline $7(3.1 \%)$ & $4(4.5 \%)$ & After 1-2 failed IVF cycles \\
\hline $232(100 \%)$ & $92(100 \%)$ & Total \\
\hline
\end{tabular}

Table 2: Hysteroscopic findings in 324 infertile women.

\begin{tabular}{|cccc|}
\hline & Normal hysteroscopy & Abnormality in hysteroscopy & $p$-value \\
\hline Age $<30$ years & 111 & 66 & 0.3498 \\
\hline$>30$ years & 100 & 47 & 0.3656 \\
\hline Primary infertility & 155 & 77 & \\
\hline Secondary infertility & 56 & 36 & \\
\hline
\end{tabular}

Table 3: Abnormal hysteroscopic findings in primary and secondary infertility group.

\begin{tabular}{|cccc|}
\hline & Primary infertility (232) & Secondary infertility (92) & $p$-value \\
\hline Cervical stenosis & 10 & 11 & 0.026 \\
\hline Cervical polyp & 2 & 3 & 0.146 \\
\hline UTERINE & & & 0.088 \\
\hline Synechia & 8 & 8 & 1.000 \\
\hline Septate uterus & 7 & 3 & 1.000 \\
\hline Submucusmyoma & 2 & 0 & 0.771 \\
\hline Deformed cavity & 10 & 5 & 0.082 \\
\hline Polyp & 0 & 2 & 0.523 \\
\hline CORNUAL & 19 & 10 & 0.182 \\
\hline Fiborsis & 10 & 8 & \\
\hline Inflammation & & & 0.286 \\
\hline ENDOMETRIAL & 5 & 4 & 0.277 \\
\hline Inflammation & 10 & 7 & 0.286 \\
\hline Fibrosis & 0 & 1 & 1.000 \\
\hline Hyperplastic & 2 & 1 & \\
\hline Atrophic & & & \\
\hline
\end{tabular}

\section{DISCUSSION}

One of the basic steps of an infertility workup is to evaluate the shape and regularity of the uterine cavity. ${ }^{6}$ Acquired uterine lesions, such as uterine fibroids, endometrial polyps, intrauterine adhesions, or all of these, may cause infertility by interfering with proper embryo implantation and growth. ${ }^{7}$ Congenital uterine malformations are also thought to play a role in delaying natural conception. ${ }^{8}$

Hysteroscopy has been proved to be the definite method for evaluation of the uterine cavity and diagnosis of associated abnormalities. ${ }^{6,9}$ Several studies have demonstrated that once the uterine cavity has to be investigated as part of the infertility workup, hysteroscopy is much more accurate than other diagnostic methods, mainly HSG. ${ }^{6}$ In the current study, this also was the main indication for performing diagnostic hysteroscopy. Based on the results of the previous studies, it appears that more than $1 / 3$ of the patients interpreted as normal following HSG are found to have a uterine abnormality after diagnostic hysteroscopy, which might be a significant cause of reproductive failure. These women may be wrongly treated, or unnecessarily investigated, while their intrauterine lesion has been missed. $^{6}$

In the current study, $35 \%$ of women, undergoing infertility evaluation, had abnormal uterine findings on 
hysteroscopy. These results are comparable to those of the other studies reporting that only $43 \%$ to $69 \%$ of infertile patients have a normal uterine cavity. ${ }^{7,10,11}$ No significant difference in the rate of uterine pathology was found between women with primary and secondary infertility (33\% and 39\%, respectively).

Complications of hysteroscopy are reported in 1 to $3 \%$ of cases. These include cervical laceration, uterine perforation, bleeding, reactions to the distention media, or anesthesia. Potential long-term complications include femoral injury resulting in intrauterine scarring or tubal obstruction, as well as injury to contiguous organs.

While the relationship between congenital uterine malformations and impaired pregnancy outcome (such as recurrent pregnancy loss, late abortions, preterm deliveries, etc.) is quite established, the issue of these malformations as a cause of infertility is still debatable. The incidence of uterine malformations in other series of infertile patients varies between $1 \%$ and $26 \%$, with a mean incidence of $3.4 \%$. We observed an incidence of $3.7 \%$ for both primary and secondary infertility. ${ }^{9}$

Donnez and Jadoul tried to address the issue of whether myomas influence fertility, by reviewing 106 relevant articles. $^{8}$ They concluded that they do influence fertility, mainly based on the favorable pregnancy rates obtained after myomectomy. Furthermore, they concluded that submucous and intramural myomas distort the cavity, impairing implantation and pregnancy rates in women undergoing IVF. Several theories have been proposed regarding this issue, including alteration of uterine contractility or induction of inflammatory and vascular changes leading to a less receptive implantation site.7 Hysteroscopy cannot only diagnose these pathologies accurately, but also enables optimal assessment for possible myomectomy. ${ }^{10}$ The reported incidence of myomas in infertile women without any obvious cause of infertility is estimated to be between $1 \%$ and $2.4 \%$. In the current study, submucous myomas were diagnosed in $0.6 \%$ of patients with secondary infertility.

Endometrial polyps were diagnosed in both primary and secondary infertility groups with no statistically significant difference. The true incidence of endometrial polyps in the general population is difficult to determine, because many of them are clinically asymptomatic. Nevertheless, Shokeir found such lesions to be more frequent in the unexplained infertility population compared with fertile women. ${ }^{12}$ The possible role of these polyps in infertility is yet unclear, although follow-up on these women revealed improved reproductive outcomes after polypectomy. He concluded, in view of his results, that it seems logical to propose surgical treatment of all endometrial polyps among eumenorrheic infertile women, since even if small, they are likely to impair fertility. Removal of these polyps may enhance reproductive outcome.
No significant difference was found in the rate of intrauterine adhesions comparing the patients with primary versus secondary infertility, in spite of the known relationship between secondary infertility and the existence of adhesions, being mostly the result of uterine curettage for postpartum or post abortion residua. Oliveira also found intrauterine adhesions in $10 \%$ of patients with repeated failed IVF cycles of whom none had undergone previous abortions or other uterine manipulation. He suggested that other causes of intrauterine adhesions must be ruled out. ${ }^{13}$

While debating the need for routine diagnostic hysteroscopy in the evaluation of the infertile woman, one must keep in mind that this procedure today is no longer a complicated but rather a simple, fast, outpatient procedure, requiring short training with high success rates.

Diagnostic hysteroscopy allows complete, accurate identification of intrauterine abnormalities that might negatively affect endometrial receptivity and implantation. The information derived from hysteroscopy helps the physician to institute appropriate therapy, and by doing so improve conception rates over shorter intervals.

Oliveira reported detection of significant, unsuspected intrauterine abnormalities, found only with hysteroscopy; in $25 \%$ of patients with repeated failed in vitro fertilization and embryo transfer (IVF-ET) cycles. ${ }^{13}$ All of his patient population had normal HSG within the former year. More importantly, relevant therapeutic interventions significantly improved the clinical pregnancy rate in those with abnormal uterine cavity at hysteroscopy. Hysteroscopy can diagnose much more precisely, compared with HSG and even transvaginal ultrasonography, small intrauterine lesions that might affect fertility.

In view of all of the above, it is clear why many authors believe that uterine and endometrial integrity should be evaluated primarily by hysteroscopy in the infertile/IVF treated population. ${ }^{11,13}$ Still, many consider hysteroscopy as only a complementary procedure in case of abnormal findings detected by other methods (primarily hysterosalpingography and ultrasound). ${ }^{8}$

\section{CONCLUSIONS}

Our results show that the incidence of uterine pathologies (congenital and acquired) in women with primary or secondary infertility approximates $35 \%$, thus, justifying, in our opinion, the use of diagnostic hysteroscopy in the primary routine investigation of infertile women. Because no significant difference was found regarding the intrauterine findings between women with primary and secondary infertility, we believe that diagnostic hysteroscopy has a similar importance in the evaluation of patients with both primary and secondary infertility. 


\section{REFERENCES}

1. Brown SE, Coddington CC, Schnorr J, Toner JP, Gibbons W, Oehninger S. Evaluation of outpatient hysteroscopy, saline infusion hysterosonography and hysterosalpingography in infertile women: a prospective, randomized study. Fertil Steril 2000;74:1029-34.

2. Gordts S, Campo R, Puttemans $\mathrm{P}$, et al. Investigation of the infertile couple. Hum Reprod 2002;17:1684-7.

3. Rowe P, Hargreave T, Mellows H. WHO Manual for the Standardized Investigation and Diagnosis of the Infertile Couple, The Press Syndicate of the University of Cambridge, Cambridge, UK, 1993.

4. de Sá Rosa e de Silva AC, Rosa e Silva JC, Cândido dos Reis FJ, Nogueira AA, Ferriani RA. Routine office hysteroscopy in the investigation of infertile couples before assisted reproduction. J Reprod Med 2005;50:501-6.

5. Koskas M, Mergui JL, Yazbeck C, Uzan S, Nizard J. Office hysteroscopy for infertility: a series of 557 consecutive cases. Obstet Gynecol Int 2010;2010:168096. doi: 10.1155/2010/168096.

6. Shushan A, Rojansky N. Should hysteroscopy be a part of the basic infertility workup? Hum Reprod 1999;14:1923-4.

7. Brown S, Coddington C, Schnorr J, Toner J, Gibbons W, Oehninger S. Evaluation of outpatient hysteroscopy, saline infusion hysterosonography and hysterosalpingography in infertile women: a prospective, randomized study. Fertil Steril 2000;74:1029-34.

8. Grimbizis GF, Camus M, Tarlatzis BS, Bontis JN, Devroey P. Clinical implications of uterine malformations and hysteroscopic treatment results. Hum Reprod 2001;7:161-74.

9. American Society for Reproductive Medicine Optimal evaluation of the infertile femalecommittee opinion. Birmingham, AL: American Society for Reproductive Medicine; June 2000.

10. Nagele F, O'Connor H, Davies A, Badawy A, Mohamed H, Magos A. 2500 outpatient diagnostic hysteroscopies. Obstet Gynecol 1996;88:87-92.

11. Pansky M, Feingold M, Sagi R, Herman A, Schneider D, Halperin R. Diagnostic hysteroscopy as a primary tool in a basic infertility workup. JSLS 2006;10:231-5.

12. Shokeir T, Shalan H, El-Shafei. Significance of endometrial polyps detected hysteroscopically in eumenorrheic infertile women. J Obstet Gynaecol Res 2004;30:84-9.

13. Oliveira FG, Abdelmassih VG, Diamond MP, Dozortsev D, Nagy ZP, Abdelmassih R. Uterine cavity findings and hysteroscopic interventions in patients undergoing in vitro fertilization-embryo transfer who repeatedly cannot conceive. Fertil Steril 2003;80:1371-5.

DOI: $10.5455 / 2320-1770$. ijrcog001512

Cite this article as: Sahu L, Tempe A, Gupta S. Hysteroscopic evaluation in infertile patients: a prospective study. Int J Reprod Contracept Obstet Gynecol 2012;1:1-5. 